\title{
AN OBSERVATIONAL STUDY- PATTERN OF PATHOGENS AND THEIR SENSITIVITY ISOLATED FROM SUPERFICIAL SURGICAL SITE INFECTIONS
}

\author{
${ }^{1}$ Senior Resident, Department of Surgery, IGIMS, Patna. \\ ${ }^{2}$ Associate Professor, Department of Surgery, IGIMS, Patna. \\ ${ }^{3}$ Senior Resident, Department of Skin and VD, NMCH, Patna. \\ ${ }^{4}$ Additional Professor, Department of Surgery, IGIMS, Patna. \\ ${ }^{5}$ Associate Professor, Department of Pharmacology, IGIMS, Patna. \\ ${ }^{6}$ Assistant Professor, Department of Pharmacology, IGIMS, Patna.
}

Yogesh Kumar Yashaswi'1, Vibhuti Bhushan², Pooja Nupur³, Pawan Kumar Jha ${ }^{4}$, Lalit Mohan', Manish Kumar

\section{ABSTRACT}

\section{BACKGROUND}

Infection is an important cause of morbidity and mortality in post-operative patients. Frequently emerging multidrug resistance and difficulty in curing patients with medications necessitates such study. Surgical Site Infections (SSI) are defined as infections that occur at the incision site within thirty days after surgery.

The objectives of the study were to determine the pattern of pathogens involved and their antibiotic sensitivity isolated from superficial surgical site infections.

\section{MATERIALS AND METHODS}

This is an observational study that was conducted for 6 months. Pus culture and sensitivity reports were collected prospectively from hospitalised patients who developed postoperative wound infections. The patients who developed faecal/biliary/urinary fistula or operated for malignancies and with negative cultures were excluded from the study. Analysis was carried out using SPSS 10 .

\section{RESULTS}

During the study period 60 patients were analysed, E. coli $36(60 \%)$ is the most common isolate in our study followed by $12(20 \%)$ Klebsiella. Staphylococcus epidermidis is the least commonly found isolate, $1(1.7 \%)$. All isolates were sensitive to penicillin derivatives and carbapenem. Quinolones, Aminoglycosides and Monobactams were also showing some promise in our study. However, Cephalosporins were ineffective against most of the important isolates in our study.

\section{CONCLUSION}

There was compelling evidence that Cephalosporins were ineffective against the common pathogens causing SSI and it is time for surgeons to court 'new' antibiotics effective against today's pathogens for both prophylaxis and empirical therapy.

\section{KEYWORDS}

Surgical Site Infections, E. coli, Antibiotic Sensitivity, Cephalosporins.

HOW TO CITE THIS ARTICLE: Yashaswi YK, Bhushan V, Nupur P, et al. An observational study- pattern of pathogens and their sensitivity isolated from superficial surgical site infections. J. Evolution Med. Dent. Sci. 2017;6(58):4308-4312, DOI: $10.14260 /$ Jemds/2017/931

\section{BACKGROUND}

In low-income countries, Surgical Site Infections (SSIs) are costly and impose a heavy and potentially preventable burden on both patients and healthcare providers.

Surgical Site Infections (SSI) are defined as an infection that occurs at the incision site within thirty days after surgery. ${ }^{1}$ SSI are infections of the tissues, organs or spaces (Intraperitoneal) contacted by surgeon. Intraoperative contamination of normally sterile tissues by pathogenic microbes is the most frequent triggering point of incision infection and it is unusual for SSI to present later than four weeks except in cases of surgical implants (Hip replacement, etc.), where it can take up.

Financial or Other, Competing Interest: None.

Submission 10-06-2017, Peer Review 07-07-2017,

Acceptance 14-07-2017, Published 20-07-2017.

Corresponding Author:

Dr. Manish Kumar,

Assistant Professor, Department of Pharmacology,

Indira Gandhi Institute of Medical Sciences,

Sheikhpura, Patna-800014, Bihar.

E-mail:manu072@gmail.com

DOI: $10.14260 /$ jemds $/ 2017 / 931$
The term SSI was proposed by the Centre for Disease Control and prevention (CDC) in 1992 following a consensus meeting of surgical infection experts and infectious disease specialists with an intension to encourage comprehensive surgical infection surveillance. 4

The CDC defines two Categories of SSI-

1. Incisional SSI comprises all infections the surgeons have traditionally named 'wound infection.'

2. Organ/space SSI are post-operative infections of body cavities or organs manipulated by surgeon.

\section{Incisional SSI can also be classified as-}

1. Superficial: The most common in modern practice and involves only subcutaneous adipose layer.

2. Deep: It is less frequent, but has more serious consequences, because these infections can spread quickly to invade the body wall, fascia and muscle. Multiple organisms are often isolated from deep incisional SSI. 
The most common organism involved is staphylococcus, as it is the most common normal skin flora. If gastrointestinal tract is violated, then E. coli and bacteroides are common.

If urinary tract is involved Group D staphylococcus, pseudomonas and proteus is the most common. ${ }^{5}$

Wound infection may be classified according to aetiology, time or severity. The infection should be considered primary unless there is a predisposing complication.6,7 Secondary infection may follow a complication which results in discharge of serum, haematoma, cerebrospinal fluid, urine, bile, pancreatic juice, gastric or intestinal contents from the wound, contaminated by bacteria from within the patient or from the environment. ${ }^{3}$

With Regard to Time, Wound Infection may be divided into-

1. Early- Presenting within 30 days of operation.

2. Intermediate- Presenting between 1 and 3 months of operation.

3. Late- Presenting more than 3 months after operation.

\section{MATERIALS AND METHODS}

This observational study was conducted for 6 months in all four surgical emergency units of Indira Gandhi Institute of Medical Sciences. Data was collected prospectively from hospitalised patients who developed postoperative wound infection. The diagnosis of wound infection was based on developing fever, pain at the operative site, wet dressing and later appearance of frank pus from the wound site usually within 5 - 7 days. The swab from infected site was collected under aseptic technique and transported in sterile, leak-proof container to central laboratory of university. All specimens were inoculated on $5 \%$ blood agar, MacConkey agar and Chocolate agar plates and incubated overnight at $37^{\circ} \mathrm{C}$ aerobically. Bacterial pathogens were identified by conventional biochemical methods according to standard microbiological techniques. Antimicrobial susceptibility was performed on Mueller-Hinton agar by the standard disk diffusion method. Data analysis was carried out using SPSS 10 .

\section{RESULTS}

During the study period, 60 culture and sensitivity reports were analysed. In this study, E. coli was the causative organism in $60 \%$ of cases followed next in frequency Klebsiella (20\%). The other isolates were Staphylococcus aureus, Pseudomonas, Enterobacter, Proteus and Staphylococcus epidermidis.

\begin{tabular}{|c|c|c|}
\hline Organism & Number (60) & Percentage (\%) \\
\hline E. coli & 36 & $60 \%$ \\
\hline Klebsiella & 12 & $20 \%$ \\
\hline S. aureus & 6 & $10 \%$ \\
\hline Pseudomonas & 3 & $5 \%$ \\
\hline Proteus & 2 & $3.3 \%$ \\
\hline S. epidermidis & 1 & $1.7 \%$ \\
\hline \multicolumn{2}{|c|}{$\begin{array}{r}\text { Table 1. Number and Percentage } \\
\text { of Organisms in Specimens }\end{array}$} \\
\hline
\end{tabular}

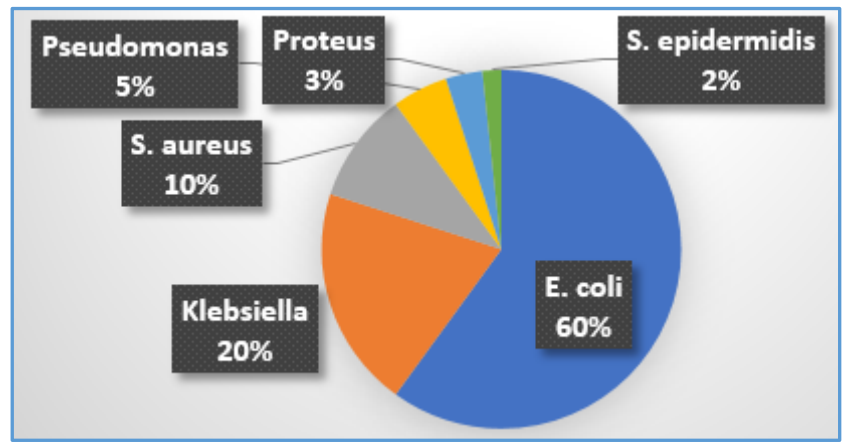

Figure 1. Percentage of Organisms in Specimens $(n=60)$

Penicillin derivatives (Piperacillin/Tazobactam) and carbapenem (Imipenem and Meropenem) are the most sensitive antibiotics covering all the organisms isolated in our study. Cephalosporins are ineffective against the common pathogens in our study and are associated with super infection except $3^{\text {rd }}$ Generation, which are showing some promise (Table 2).

\begin{tabular}{|c|c|c|c|c|c|c|c|c|c|c|c|c|}
\hline \multirow[t]{2}{*}{ Antibiotics } & \multicolumn{2}{|c|}{$\begin{array}{c}\text { E. coli } \\
(n=36)\end{array}$} & \multicolumn{2}{|c|}{$\begin{array}{c}\text { Klebsiella } \\
(n=12)\end{array}$} & \multicolumn{2}{|c|}{$\begin{array}{c}\text { S. aureus } \\
(n=6)\end{array}$} & \multicolumn{2}{|c|}{$\begin{array}{l}\text { Pseudomonas } \\
(n=3)\end{array}$} & \multicolumn{2}{|c|}{$\begin{array}{c}\text { Proteus } \\
(n=2)\end{array}$} & \multicolumn{2}{|c|}{$\begin{array}{l}\text { S. epidermidis } \\
(n=1)\end{array}$} \\
\hline & $\mathbf{S}$ & $\mathbf{R}$ & $\mathbf{S}$ & $\mathbf{R}$ & $\mathbf{S}$ & $\mathbf{R}$ & $\mathbf{S}$ & $\mathbf{R}$ & $\mathbf{S}$ & $\mathbf{R}$ & $\mathbf{S}$ & $\mathbf{R}$ \\
\hline Penicillin & 30 & 6 & 8 & 4 & 6 & 0 & 3 & 0 & 2 & 0 & 1 & 0 \\
\hline Carbapenems & 36 & 0 & 12 & 0 & 6 & 0 & 3 & 0 & 2 & 0 & 1 & 0 \\
\hline Quinolones & 18 & 18 & 7 & 5 & 6 & 0 & 1 & 2 & 2 & 0 & 1 & 0 \\
\hline Monobactams & 26 & 10 & 7 & 5 & 3 & 3 & 1 & 2 & 2 & 0 & 1 & 0 \\
\hline Cephalosporins & 10 & 26 & 4 & 8 & 4 & 2 & 2 & 1 & 0 & 2 & 0 & 1 \\
\hline Aminoglycosides & 18 & 18 & 10 & 2 & 6 & 0 & 2 & 1 & 1 & 1 & 0 & 1 \\
\hline Glycopeptides & 0 & 36 & 0 & 12 & 6 & 0 & 0 & 3 & 0 & 2 & 0 & 1 \\
\hline Macrolides & 0 & 36 & 0 & 12 & 2 & 4 & 0 & 3 & 0 & 2 & 0 & 1 \\
\hline
\end{tabular}

S-Sensitive, R-Resistant. 


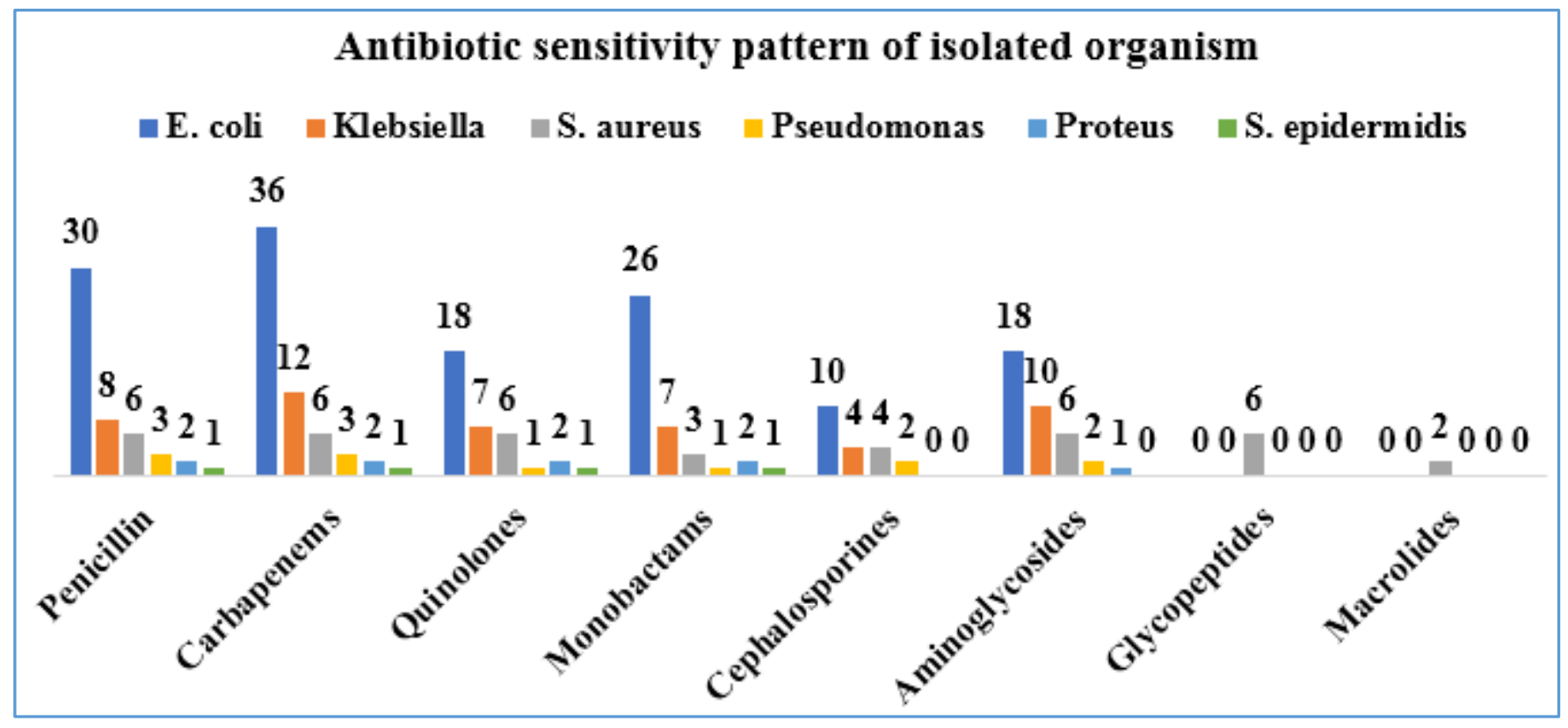

Figure 2. Antibiotic Sensitivity Pattern of Isolated Organism

\section{Antibiotic resistance pattern of isolated organism}

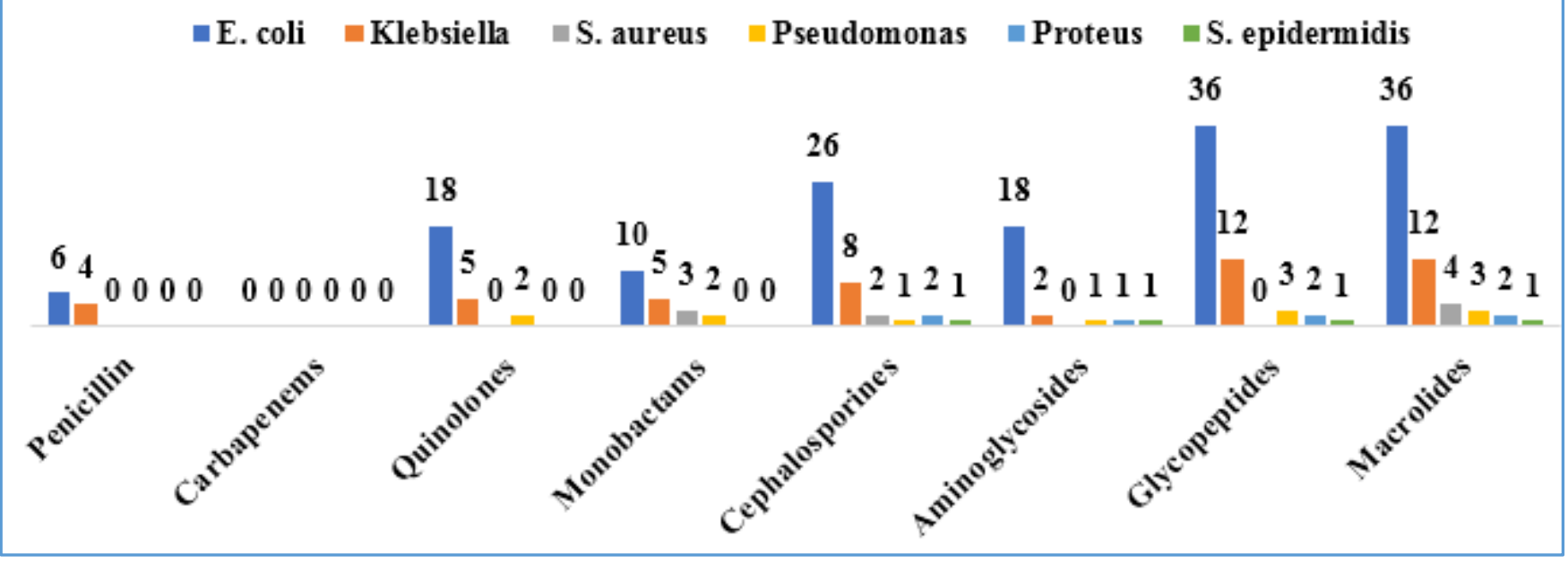

Figure 3. Antibiotic Resistance Pattern of Isolated Organism

\section{DISCUSSION}

Operative site infection is very common in post-operative period. In our hospital, mainly people of low socioeconomic group visit and that too with medical comorbidities like diabetes, cardiovascular complications which attributes to comparably larger number of cases in Bihar. Surgical site infection is responsible for delay in discharge and loss of finance also, therefore care for prevention of post-surgical infections should be done. In fact wound infection adds approximately more than 6000 US dollars to the hospital cost and more than 7 days' hospital stay with consequent delay to return to work. ${ }^{8,9}$

In this study the frequently isolated organism was E. coli (60\%) in contrast to the Nosocomial Infection National Surveillance Service (NINSS) survey (1997 - 2001), which report Staphylococcus (47\%) including Staphylococcus aureus (MRSA) and Staphylococcus epidermidis (Coagulase negative) as the most common organism causing SSI.10,11
An explanation to the above finding could be that in most of our surgical procedures, the gastrointestinal tract was violated and results in contamination of the wound edges at the time of surgery.

We found Staphylococcus aureus $100 \%$ sensitive to glycopeptides (vancomycin), a finding that is identical to other national studies. ${ }^{10,11}$ Pseudomonas also showed a maximum sensitivity to penicillin derivatives (Piperacillin/Tazobactam) in our study as already reported in other International studies. ${ }^{12,13}$ Third generation Cephalosporin (ceftazidime) and Aminoglycoside (gentamicin) has a potent anti-pseudomonas activity. ${ }^{14,15}$ The antibiotic sensitivity of other isolates showed a variable pattern. Cephalosporins are ineffective against most of the pathogens isolated in our study. Surgical Site Infections (SSI) are an important postoperative complication second only to urinary tract infection. It has been estimated that SSI develop in $2 \%$ to $5 \%$ of patients undergoing clean extra-abdominal 
operations and upto $20 \%$ undergoing intra-abdominal operations. ${ }^{1,2}$ Perioperative antibiotic prophylaxis is widely used to reduce the occurrence of SSI.

Antibiotics should be used for actual infections and not for colonisation or prolonging the duration of surgical prophylaxis for clean cases. It is a common knowledge that antibiotics are used indiscriminately. This inappropriate antibiotic usage increases the selective pressure favouring the emergence of antimicrobial resistance and colonisation of drug resistant strains. ${ }^{3,16}$

Appropriate antibiotic prophylaxis ensures that adequate concentrations of an antimicrobial are present in the serum, tissue and wound during the entire time that the incision is open and at risk of bacterial contamination. ${ }^{17}$ We need data to generate local susceptibility patterns to reduce rates of SSI and compare with standard guidelines. These guidelines encompass the correct drug, timing, dose and duration of antibiotics.

\section{Optimal Surgical Antimicrobial Prophylaxis must take} into Consideration the following Three Factors-

1. Appropriate choice of antibiotics. ${ }^{18}$

2. Proper timing of antimicrobial prior to the incision.

3. Limiting the duration of antimicrobial administration after surgery.

The choice of drug has to do with its clinical efficacy and whether it is safe, inexpensive and has a wide spectrum. It should be active against the pathogen most commonly associated with wound infections following a specific procedure and against the pathogens endogenous to the region of body being operated on. ${ }^{5}$

For elective clean procedure using a foreign body and in clean contaminated procedures, it is generally recommended that a single dose of cephalosporin be administered intravenously by anaesthesia personnel in the operative suit just before the incision.

It is important that antibiotic infusion is timed, so the optimal concentration is in the serum/tissue at the time of the incision. It is equally important to maintain that therapeutic level in the serum/tissue throughout the operation. If the surgical procedure is longer than the half-life of the drug, the drug must be re-dosed during the procedure.

Historically, the drug should be given during the interval between 30 minutes and two hours before the time of surgical incision. The most recent Medical Letter recommendations are that the drug be given no more than 30 minutes before the skin is incised.

Discontinuation of Antibiotic within 24 hours after Surgery is recommended for Two Reasons-

1. Use of surgical prophylaxis antimicrobial agent past this time frame has not been shown to improve SSI rates and increases the cost of care unnecessarily.

2. Indiscriminate use of antibiotics can lead to antibiotic resistant microorganisms.

The Centre of Medicare and Medicaid Services (CMS) and the CDC have developed a new national healthcare quality improvement project to prevent postoperative infection. ${ }^{16,19}$ The Surgical Infection Prevention (SIP) Project was rolled out via the Quality Improvement Organisations (QIOs) in all 50 states in August 2002. The focus of this project was the prevention of SSIs through the optimal selection and timing of prophylactic antibiotics administration, both known to be important in effective prophylaxis.

\section{The Indicators of the Project Included-}

- The proportion of patients who received prophylactic antibiotics within one hour before surgical incision.

- The proportion of patients given an antibiotic consistent with current recommendations.

- The proportion of patients who received prophylactic antibiotics whose antibiotics were discontinued within 24 hours after surgery.

Although surgical site infection is a relatively serious problem in our health institution, there are scanty published reports on the bacterial pathogens that are involved in SSIs in our local hospitals. The sporadic reports from the publicsector hospitals are mainly from the microbiology laboratory records, which may not show the complete clinical picture. Paucity of published data on risk factors for SSIs has impacted negatively on management of patients, particularly in the resource strained setup. Data from this study could be used to benchmark for a large-scale study that could be useful for the policy makers to make informed decisions on issues of infection control pertaining to surgical wound sepsis.

\section{CONCLUSION}

There is compelling evidence that Cephalosporins are ineffective against the common pathogens causing SSI and it is time for surgeons to court 'new' antibiotics effective against today's pathogens for both prophylaxis and empirical therapy.

We suggest that surgeon, pharmacist, epidemiologist and microbiologist to take local infecting organism/sensitivity pattern into account when formulating prophylaxis as well as empirical therapy guideline for individual surgical site. Also, the chosen antibiotic must have antimicrobial susceptibility for the common prevalent stains of microorganisms.

\section{REFERENCES}

[1] Mangram AJ, Horan TC, Pearson ML, et al. Guideline for prevention of surgical site infection, 1999. Hospital Infection Control Practices Advisory Committee. Infect Control Hosp Epidemiol 1999;20(4):247-80.

[2] Lee J. Wound infection surveillance for quality improvement In: Fry D. edr. Surgical infection. New York: Little Brown 1995:145-59.

[3] Lee JT. Wound infection surveillance. Infect Dis Clin North Am 1992;6(3):643-56.

[4] Garibaldi RA, Cushing D, Lerer T. Risk factors for postoperative infection. Am J Med 1991;91(3B):158S$63 \mathrm{~s}$.

[5] Horan TC, Gaynes RP, Martone WJ, et al. CDC definitions of nosocomial surgical site infections, 1992: a modification of CDC definitions of surgical wound infections. Infect Control Hosp Epidemiol 1992;13(10):606-8.

[6] Barie PS, Eachempati SR. Surgical site infections. Ann KE Med Coll 2005;11:263-7. 
[7] Klevens RM, Edwards JR, Richards CL, et al. Estimating health care associated infections and deaths in U.S. hospitals, 2002. Public Health Rep 2007;122(2):160-6.

[8] Lee J, Olson M. Wound infection surveillance for 85,260 consecutive operations. J Surg Outcomes 1999;2:27-42.

[9] Olson MM, Lee JT. Continuous, ten year wound infection surveillance: results, advantages and unanswered questions. Arch Surg 1990;125(6):794803.

[10] Weber DJ, Raasch R, Rutala WA. Nosocomial infection in the ICU: the growing importance of antibioticresistance pathogens. Chest 1999;115(Suppl 3):34S$41 \mathrm{~S}$.

[11] Olson M, O'Connor M, Schwartz ML. Surgical wound infections. A 5-year prospective study of 20,193 wounds at the Minneapolis VA Medical Center. Ann Surg 1984;199(3):253-9.

[12] Surveillance of surgical site infections in English hospitals 1997-2001. Nosocomial Infection National Surveillance Service (NINSS). PHLS publications 2001.

[13] Crowcroft NS, Ronveaux O, Monnet DL, et al. Methicillin-resistant Staphylococcus aureus and antimicrobial use in Belgian Hospitals. Infect Control Hosp Epidemiol 1999;20(1):31-6.
[14] Qureshi AH, Rafi S, Qureshi SM, et al. The current susceptibility pattern of MRSA to conventional antistaphylococcus antimicrobials at Rawalpindi. Pak J Med Sci 2004;20:361-4.

[15] Majeed MT, Izhar M. Glycopeptides sensitivity pattern in staphylococci isolated from clinical specimens in a tertiary care hospital setting. Am J Infect Control 2008;36:309-3.

[16] World Health Organization. Prevention of hospitalacquired infections. A practical guide $2^{\text {nd }}$ edn. WHO/CDS/CSR/EPH/2002.12.

[17] Barie PS. Surgical site infections: epidemiology and prevention. Surg Infect (Larchmt) 2002;3(Suppl 1): S9-1.

[18] Adhikary R, Gokul BN, Kulkarni KR, et al. Monitoring of antibiotic prophylaxis usage in a tertiary care hospital. International Journal of Infectious Diseases 2008;12(Suppl 1):e413-e4.

[19] Horan TC, Andrus M, Dudeck MA. CDC/NHSN surveillance definition of healthcare-associated infection and criteria for specific types of infections in the acute care setting. Am J Infect Control 2008;36(5):309-32. 
